\title{
Épocas de corte e a produtividade em genótipos de cana-de-açúcar, em cana-soca ${ }^{1}$
}

\section{Harvest dates and the productivity in sugarcane genotypes, in first ratoon}

\author{
Paulo Mauricio Centenaro Bueno ${ }^{2}$; Edelclaiton Daros ${ }^{3 *}$; \\ Ricardo Augusto de Oliveira ${ }^{3}$; José Luis Camargo Zambon ${ }^{3}$; \\ João Carlos Bespalhok Filho ${ }^{3}$; Heroldo Weber $^{3}$
}

\section{Resumo}

\begin{abstract}
A cana-de-açúcar apresenta comportamento diferenciado quando submetida a diferentes ambientes de produção e épocas de corte. Este trabalho auxiliará na escolha da época mais adequada de colheita de cada genótipo, de modo que expresse seu maior potencial agroindustrial. O objetivo do presente trabalho foi avaliar a produtividade agroindustrial de genótipos de cana-de-açúcar em diferentes épocas de corte em cana-soca, no ano de 2007. O experimento foi instalado em 15 de março de 2005, na Usina Alto Alegre, no município de Colorado, região noroeste do estado do Paraná. O local do experimento possui solo classificado como latossolo vermelho-amarelo, e clima classificado como Cfa, segundo a classificação de Köppen. $\mathrm{O}$ delineamento experimental utilizado foi o inteiramente casualizado em arranjo fatorial $3 \times 10$, sendo três épocas de corte (abril, julho, e outubro) e dez genótipos. Foram avaliados Pol \% cana (polarização do açúcar), TCH (tonelada de cana por hectare) e TPH (tonelada de Pol por hectare). A parcela experimental foi constituída por quatro sulcos, com espaçamento de $1,10 \mathrm{~m}$, com oito metros de comprimento, e 18 gemas por metro linear. Nas condições do presente trabalho, houve interação significativa entre épocas de corte, e genótipos, sendo que os genótipos sofreram influência das épocas de corte quanto à produtividade agroindustrial. A tomada de decisões para colher os genótipos de canade-açúcar não deve ser baseada apenas nos padrões tecnológicos, pois um alto valor de Pol \% cana pode não significar alta produtividade agroindustrial.
\end{abstract}

Palavras-chave: Saccharum spp., cultivar, colheita, maturação

\begin{abstract}
The sugarcane shows different performances when submitted to different production environments and harvest dates. This work will assist in choosing the better harvest date for each genotype, in a way to show its greater agro-industrial potential. The aim of this work was to evaluate sugarcane genotypes' agro-industrial productivity in different harvest dates, in first ratoon, in the year of 2007. The experiment was installed on march $15^{\text {th }}, 2005$, at the Usina Alto Alegre, in Colorado, northwest of Paraná State. The experiment's place has ground classified as latossolo vermelho-amarelo, and climate classified as Cfa, according to Köppen classification. The statistical design used was completely randomized design in factorial arrangement of $3 \times 10$, being three harvest dates (April $15^{\text {th }}$, July $15^{\text {th }}$ and October $15^{\text {th }}$ ) and ten
\end{abstract}

\footnotetext{
${ }^{1}$ Parte da dissertação de mestrado do primeiro autor, apresentada ao Programa de Pós-Graduação em Agronomia. Produção Vegetal, da Universidade Federal do Paraná.

${ }^{2}$ Eng $^{\circ}$ Agr $^{\circ}$, Mestre, Doutorando em Produção Vegetal, Morfogênese e Biotecnologia de Plantas, Universidade Federal do Paraná, UFPR, Cutiriba, PR. E-mail: paulobueno@ufpr.br

${ }^{3}$ Engenheiros Agrônomos, Drs. da UFPR, Dept ${ }^{\circ}$ de Fitotecnia e Fitossanitarismo. Curitiba, PR. E-mail: ededaros@ufpr.br; rico@ ufpr.br; joseluis@ufpr.br; bespa@ufpr.br; heroldo@ufpr.br

* Autor para correspondência
} 
genotypes. It was evaluated Pol \% cana (sugar polarization), TCH (ton ha ${ }^{-1}$ of cane) and TPH (ton ha ${ }^{-1}$ of Pol). The experimental plot was composed by four rows, with 1,10 meters between each row and 8,0 meters of length, and 18 buds per linear meter. In the conditions of the present work, there was significant interaction between harvest dates and genotypes, considering that the genotypes suffered influence from the harvest dates in its agro-industrial productivity. The decision of the harvest date of each sugarcane genotype must not be based only on the technological standards, therefore, a high value of Pol can cannot mean high agro-industrial productivity.

Key words: Saccharum spp., cultivate, season, cut, ripening

\section{Introdução}

A cana-de-açúcar é cultivada em regiões tropicais e subtropicais de mais de 90 países (TAVARES, 2009), e no Brasil, no ano de 2009, a cultura já ocupava mais de oito milhões de hectares, produzindo mais de 556 milhões de toneladas de cana por safra, sendo o líder mundial na utilização dessa planta como fonte de energia renovável. Trata-se da fonte de álcool e açúcar mais barata pelo fato de a energia consumida para a sua obtenção ser proveniente do bagaço da própria cana (MAPA, 2007).

O Estado do Paraná produz cerca de 52 milhões de toneladas de cana-de-açúcar em mais de 610 mil hectares, sendo que a produtividade média do Estado é de 85 toneladas de cana por hectare (CONAB, 2008, citado por DIAS, 2008).

A cana-de-açúcar é remunerada, atualmente, pela qualidade em açúcar teórico recuperável (ATR), que utiliza como base a Pol \% cana e a pureza do caldo, e seu resultado é expresso em quilogramas de açúcar por tonelada de cana. Essa forma de remuneração é diferente da utilizada antigamente quando pagavase pela produção agrícola (toneladas de cana por hectare), o que nem sempre correspondia à máxima produção industrial (CONSECANA, 1999). Portanto, é de interesse da usina colher maiores quantidades de açúcar por unidade de área. $\mathrm{O}$ planejamento da época de corte da cana-de-açúcar é uma ferramenta utilizada para obter a maior riqueza de açúcar, resultando em maior retorno econômico (ALENCAR; CORRÊA; LIMA NETO, 2006).

A cada ciclo da cultura da cana-de-açúcar, as plantas são submetidas a diferentes condições ambientais como alterações de temperaturas e excesso ou deficiência hídrica, além de diversas práticas de manejo da cultura, como a escolha da época de corte, entre outras. Essas condições ambientais e de manejo irão proporcionar às plantas diferentes respostas, podendo ter efeito direto em sua produtividade agroindustrial (MENDONÇA; NOCITI; DEOTTI, 1984; COPERSUCAR, 1983).

Considerando que vários genótipos de cana-deaçúcar são cultivados nas usinas canavieiras, é de extrema importância saber qual é o período em que cada um possui maior riqueza em açúcares, o que irá auxiliar na tomada de decisões da época em que os mesmos serão colhidos. O objetivo do presente trabalho foi avaliar a produtividade agroindustrial de genótipos de cana-de-açúcar em diferentes épocas de corte, em cana-soca, no ano de 2007. Foram testados diferentes genótipos de cana-deaçúcar quanto à sua produtividade agroindustrial em três épocas de colheita, na Usina Alto Alegre, no município de Colorado - PR, região noroeste do Estado do Paraná.

\section{Material e Métodos}

O experimento foi conduzido a campo de 2005 a 2007 na Usina Alto Alegre S/A, localizada no Município de Colorado, PR, região noroeste do Estado, entre as coordenadas de $22^{\circ} 54^{\prime}$ de latitude Sul e $51^{\circ} 56^{\prime}$ de longitude Oeste, com altitude média de $490 \mathrm{~m}$.

A região apresenta, segundo a classificação de Köeppen, clima tipo Cfa, subtropical, com temperatura média inferior a $18^{\circ} \mathrm{C}$ no mês mais frio (mesotérmico) e temperatura média no mês mais 
quente acima de $22^{\circ} \mathrm{C}$, com verões quentes, geadas pouco freqüentes e tendência de concentração das chuvas nos meses de verão, contudo sem estação seca definida e precipitação média anual de 1.300 a $1.400 \mathrm{~mm}$ (IAPAR, 1994).

O experimento foi instalado em solo tipo Latossolo Vermelho Distrófico (LVd-1) (PRADO, 2003), com relevo suave ondulado. São solos muito profundos, formados a partir de materiais derivados de arenitos, com seqüência de horizontes A, B, C pouco diferenciados, coloração vermelha escura, porosos, muito friáveis, fortemente drenados, baixa fertilidade natural, ácidos, mas de baixo a médio teor de alumínio trocável e saturação de bases baixa (EMBRAPA, 1999; PRADO, 2003).
Os dados que compuseram o balanço hídrico foram obtidos da estação meteorológica do IAPAR/ SIMEPAR, no município de Paranavaí, PR, entre os períodos de março de 2005 a dezembro de 2008.

Cada parcela experimental foi composta por quatro sulcos, de 8,0 metros de comprimento cada, com espaçamento entre sulcos de 1,10 metros.

O plantio dos genótipos de cana-de-açúcar foi realizado em 15 de março de 2005, que são denominados de genótipos de ciclo precoce: considerando que sua colheita é recomendada entre abril e junho; genótipos de ciclo médio, considerando que sua colheita é recomendada de junho a setembro, e genótipos de ciclo tardio, cuja época recomendada de colheita é entre os meses de setembro e dezembro, como está apresentado na Tabela 1 .

Tabela 1. Relação dos ambientes de produção e de épocas de colheita recomendadas para os dez genótipos de canade-açúcar utilizados em cana-soca e ressoca. Município de Colorado, PR. 2010.

\begin{tabular}{llllllllllllll}
\hline \multirow{2}{*}{ Genótipos } & \multicolumn{1}{c}{ Ambiente de Produção } & \multicolumn{1}{c}{ Época de Colheita } \\
& A & B & C & D & Abr & Mai & Jun & Jul & Ago & Set & Out & Nov & Dez \\
\hline RB835054 & X & X & X & & X & X & X & X & & & & & \\
RB925211 & X & X & X & & & X & X & X & & & & \\
RB946903 & X & X & X & & & X & X & X & X & & & \\
RB956911 & X & X & X & & & X & X & X & & & & \\
RB966928 & X & X & X & & X & X & X & X & X & & & & \\
RB845210 & & X & X & X & & X & X & X & X & X & & & \\
RB855113 & & X & X & X & & & X & X & X & X & & & \\
SP81-3250 & X & X & X & & & & & X & X & X & X & X & \\
RB935744 & X & X & X & & & & & & X & X & X & X & X \\
RB72454 & X & X & X & X & & & & & X & X & X & X & X \\
\hline
\end{tabular}

Fonte: Adaptado de catálogo anual RIDESA e COPERSUCAR.

No preparo do solo, foram realizadas duas gradagens, sendo a primeira com grade aradora, e a segunda com grade niveladora. Em seguida foi feita a sulcação para o plantio dos colmos, provindos de mudas com dez meses de idades plantadas em viveiro localizado na unidade. A adubação de base utilizada foi $80 \mathrm{~kg} \mathrm{ha}^{-1}$ de $\mathrm{N}, 150 \mathrm{~kg} \mathrm{ha}^{-1}$ de $\mathrm{P}_{2} \mathrm{O}_{5}$ e $120 \mathrm{~kg} \mathrm{ha}^{-1}$ de $\mathrm{K}_{2} \mathrm{O}$. Nas adubações de soca e ressoca subseqüentes foi utilizado $120 \mathrm{~kg} \mathrm{ha}^{-1}$ de $\mathrm{N}$ e $120 \mathrm{~kg}$ $\mathrm{ha}^{-1}$ de $\mathrm{K}_{2} \mathrm{O}$.
O plantio foi manual (convencional), onde os colmos foram distribuídos dentro das linhas de plantio (sulcos), pé com ponta, sendo colocadas duas canas por metro linear, totalizando na média 18 gemas por metro linear.

Os tratos culturais de adubação em cobertura e controle de plantas daninhas da cana planta, canasoca e ressoca, foram os utilizados pela usina, não havendo necessidade de controle de pragas. 
Os tratamentos utilizados foram as diferentes épocas de corte, sendo o primeiro tratamento, com o corte da cana-planta no dia 15 de abril, o segundo tratamento foi o corte da cana-planta no dia 15 de julho, e o terceiro, em 15 de outubro de 2006.

A colheita dos dados ocorreu exatamente 12 meses após o corte da cana-planta, ou seja nos dias 15 de abril, 15 de julho, e 15 de outubro de 2007.

Em cada época de corte foram avaliados tonelada de cana por hectare $(\mathrm{TCH})$, Pol \% cana (POL) e tonelada de Pol por hectare (TPH). A variável TCH: estimada em função da massa média de um colmo da parcela, em kg, o número total de colmos presentes nas respectivas parcelas e um fator que é em função do espaçamento de plantio, conforme evidencia a seguinte fórmula: $\mathrm{TCH}=\mathrm{M} 1 \mathrm{C} \mathrm{x} \mathrm{NCM} \mathrm{x}$ $(100 / 1,10)$ x 100/1000. Sendo que 1,10 refere-se ao espaçamento entre linhas, 100 refere-se aos metros lineares de um hectare, e 1000 é a correção de quilos para toneladas. A variável foi TPH determinada em função da tonelada de cana por hectare e o teor de POL cana, conforme descreve a fórmula a seguir: $\mathrm{TPH}=(\mathrm{TCH} \times \mathrm{POL}) / 100$. A variável POL foi obtida por meio da seguinte fórmula:

$$
\text { Pol }=\left(a / c+1-0,01 \times \text { Fib }_{d}\right),
$$

em que $a=1000 \mathrm{~g} \mathrm{H}_{2} 0, c=500 \mathrm{~g}$ de cana, e $F i b_{d}=$ teor de fibra da cana obtida pelo método do digestor.

$\mathrm{O}$ delineamento experimental utilizado foi o inteiramente casualizado em arranjo fatorial $3 \times 10$, sendo três épocas de corte, dez genótipos e três repetições.

Os resultados das avaliações foram submetidos à análise de variância, utilizando para isso o programa estatístico SISVAR ${ }^{\circledR}$ aos níveis de 5\% e $1 \%$ de probabilidade. Quando os dados eram significativos, as médias foram comparadas pelo teste de ScottKnott ao nível de 5\% de probabilidade (BORGES; FERREIRA, 2003).

\section{Resultados e Discussão}

Como a interação entre épocas de colheita e genótipos na cana-soca foi significativa (Tabela 2), as fontes de variação não são independentes, sendo que os genótipos se comportaram de forma diferente em cada época de colheita. Por isso, não é possível apontar o melhor genótipo ou a melhor época sem que ambos sejam relacionados.

Tabela 2. Resultados da análise de variância para tonelada de cana por hectare (TCH), tonelada de pol por hectare (TPH) e pol cana (POL) em cana-soca, para dez genótipos de cana-de-açúcar, colhidos em abril, julho e outubro de 2007, na Unidade Alto Alegre, Colorado, PR.

\begin{tabular}{llccc}
\hline \multirow{2}{*}{ Fonte de Variação } & \multirow{2}{*}{ Graus de Liberdade } & \multicolumn{3}{c}{ QUADRADOS MÉDIOS } \\
\cline { 3 - 5 } & & TCH & TPH & POL \\
\hline ÉPOCA & 2 & $14746,710^{* *}$ & $545,217^{* *}$ & 76,869 \\
GENÓTIPO & 9 & $1545,001^{* *}$ & $37,481^{* *}$ & 0,756 \\
ÉPOCA*GENÓTIPO & 18 & $699,297^{* *}$ & $20,596^{* *}$ & 1,058 \\
\hline Erro & 60 & 84,787 & 2,332 & 0,418 \\
\hline Coeficiente de Variação & & $9,40 \%$ & $10,11 \%$ & $4,22 \%$ \\
\hline
\end{tabular}

* - significativo ao nível de 5\% de probabilidade

** - significativo ao nível de $1 \%$ de probabilidade

Fonte: Elaboração dos autores. 
Desempenho de cada genótipo quando colhido em abril

Os valores de TCH, TPH e Pol \% cana dos dez genótipos selecionados, colhidos no mês de abril de 2007, estão apresentados na Tabela 3.

A colheita da cana-soca no mês de abril de 2007 proporcionou aos genótipos RB925211, RB966928 (de ciclo precoce), RB855113 e SP81-3250 (de ciclo médio) a maior produtividade agrícola $(\mathrm{TCH})$ em relação aos demais.

Silva, Jerônimo e Lúcio (2008) não observaram diferenças entre os valores de TCH e TPH dos genótipos RB72454 (83,49 e 10,98, respectivamente) e IAC86-2480 (79,16 e 10,34, respectivamente), em cana-soca, quando colhidos no mês de maio.

Tabela 3. Valores de tonelada de cana por hectare (TCH), tonelada de pol por hectare (TPH) e Pol \% cana (POL) de cana-soca, de dez genótipos colhidos em abril de 2007 na Unidade Alto Alegre, Colorado, PR.

\begin{tabular}{cccccccc}
\hline Genótipo & Ciclo & TCH & & TPH & \multicolumn{2}{c}{ POL } \\
\hline RB835054 & P & 68,28 & b & 9,45 & $\mathrm{c}$ & 13,87 & $\mathrm{a}$ \\
RB925211 & P & 97,75 & $\mathrm{a}$ & 14,07 & $\mathrm{a}$ & 14,39 & $\mathrm{a}$ \\
RB946903 & $\mathrm{P}$ & 78,70 & $\mathrm{~b}$ & 11,52 & $\mathrm{c}$ & 14,62 & $\mathrm{a}$ \\
RB956911 & $\mathrm{P}$ & 70,68 & $\mathrm{~b}$ & 10,04 & $\mathrm{c}$ & 14,20 & $\mathrm{a}$ \\
RB966928 & $\mathrm{P}$ & 108,97 & $\mathrm{a}$ & 15,49 & $\mathrm{a}$ & 14,16 & $\mathrm{a}$ \\
RB845210 & $\mathrm{M}$ & 85,91 & $\mathrm{~b}$ & 11,22 & $\mathrm{c}$ & 13,09 & $\mathrm{~b}$ \\
RB855113 & $\mathrm{M}$ & 100,28 & $\mathrm{a}$ & 12,28 & $\mathrm{~b}$ & 12,26 & $\mathrm{~b}$ \\
SP81-3250 & $\mathrm{M}$ & 95,53 & $\mathrm{a}$ & 12,64 & $\mathrm{~b}$ & 13,19 & $\mathrm{~b}$ \\
RB935744 & $\mathrm{M}$ & 87,35 & $\mathrm{~b}$ & 11,12 & $\mathrm{c}$ & 12,77 & $\mathrm{~b}$ \\
RB72454 & $\mathrm{T}$ & 80,63 & $\mathrm{~b}$ & 9,97 & $\mathrm{c}$ & 12,36 & $\mathrm{~b}$ \\
\hline CV (\%) & & 10,28 & & 10,56 & & 4,03 & \\
\hline
\end{tabular}

Médias seguidas pela mesma letra na vertical não diferem estatisticamente pelo teste de Scott-Knott a 5\% de probabilidade.

P: Precoce. M: Médio. T: Tardio

CV: Coeficiente de Variação

Fonte: Elaboração dos autores.

As maiores médias de Pol \% cana foram obtidas por genótipos de ciclo precoce, sendo eles: RB835054, RB925211, RB946903, RB956911 e RB966928, os quais não diferiram estatisticamente entre si. Esse resultado já era esperado, visto que os referidos materiais apresentam recomendação de corte de abril até junho.

Quanto à variável TPH, os genótipos RB925211 e RB966928 se destacaram, obtendo as maiores médias em relação aos demais. Trata-se de dois genótipos de ciclo precoce.

Percebe-se que apenas um alto valor de Pol $\%$ cana pode não garantir uma alta produtividade agroindustrial observando o comportamento do genótipo RB835054, o qual apresentou um alto valor de Pol \% cana (13,87\%), porém seu valor de TPH esteve entre os menores $\left(9,45 \mathrm{t} \mathrm{ha}^{-1}\right)$, devido à baixa produtividade agrícola $(\mathrm{TCH})$, que foi de $68,28 \mathrm{t} \mathrm{ha}^{-1}$.

As baixas produtividades da maioria dos genótipos são justificadas pelas condições ambientais desfavoráveis ao desenvolvimento da cana-de-açúcar, observadas no período de desenvolvimento da cana-soca colhida no mês de abril de 2007. As soqueiras foram submetidas a um ambiente desfavorável ao desenvolvimento inicial das plantas, aliando deficiência hídrica (Figura 1) e baixas temperaturas (Figura 2) (BARBIERI; VILLA NOVA, 1977; LIU; KINGSTON; BULL, 1998; BEZUIDENHOUT et al., 2003; ALMEIDA et al., 2008; SILVA; Jerônimo e Lúcio, 2008). 
Figura 1. Balanço hídrico (Deficiência, Excedente, Retirada e Reposição Hídrica) mensal de abril de 2006 a outubro de 2007, em Colorado, no estado do Paraná.

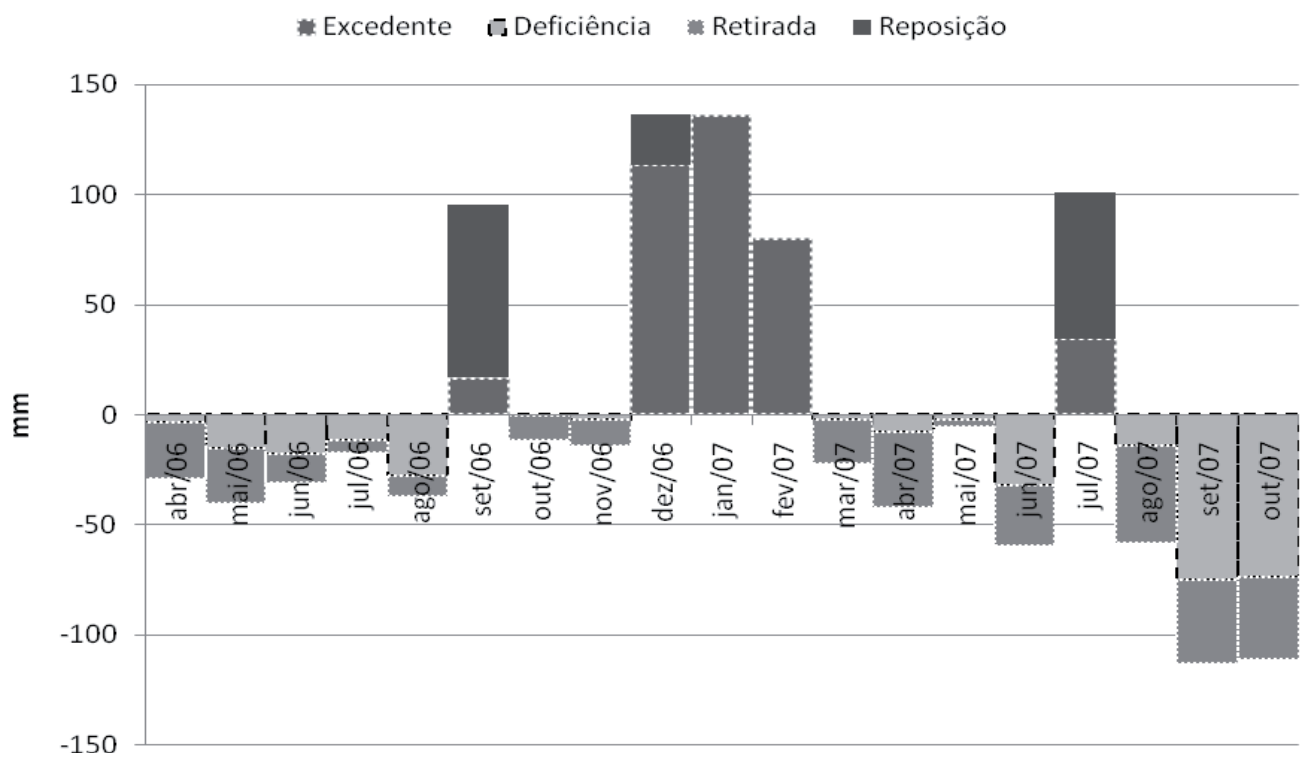

Fonte: Elaboração dos autores, com dados fornecidos pelo IAPAR/SIMEPAR.

Figura 2. Valores de temperaturas máximas, mínimas e médias $\left({ }^{\circ} \mathrm{C}\right)$ mensais de abril de 2006 a outubro de 2007, em Colorado, no estado do Paraná.

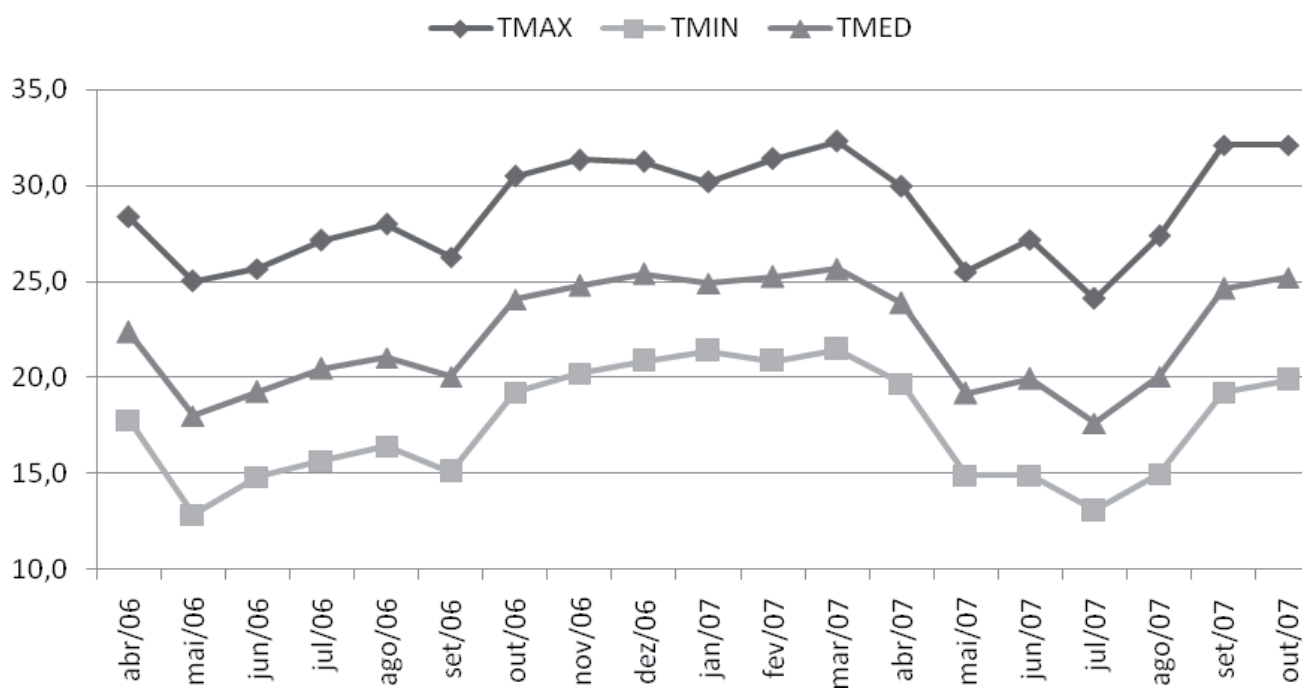

Fonte: Elaboração dos autores, com dados fornecidos pelo IAPAR/SIMEPAR.

Desempenho de cada genótipo quando colhido em julho

Os valores de TCH, TPH e Pol \% cana dos dez genótipos selecionados, colhidos no mês de julho de 2007, estão apresentados na Tabela 4.
Os dez genótipos colhidos, em cana-soca, no mês de julho apresentaram comportamentos semelhantes quanto à variável Pol \% cana, sendo que não apresentaram diferenças significativas entre si. 
Já no caso de TCHe TPH, os genótipos RB966928 (de ciclo precoce), RB935744 (de ciclo médio) e RB72454 (de ciclo tardio) obtiveram as maiores médias, os quais não diferiram estatisticamente entre si, e foram superiores às médias dos demais genótipos.
Silva, Jerônimo e Lúcio (2008) obtiveram com o genótipo RB72454, em cana-soca, os maiores valores de TCH e TPH, comparando com os valores do genótipo IAC86-2480, quando colhidos no mês de julho.

Tabela 4. Valores de tonelada de cana por hectare (TCH), tonelada de pol por hectare (TPH) e Pol \% cana (POL) de cana-soca, de dez genótipos colhidos em julho de 2007 na Unidade Alto Alegre, Colorado, PR.

\begin{tabular}{cccccccc}
\hline Genótipo & Ciclo & TCH & & TPH & \multicolumn{2}{c}{ POL } \\
\hline RB835054 & P & 115,84 & $\mathrm{c}$ & 18,22 & $\mathrm{c}$ & 15,75 & $\mathrm{a}$ \\
RB925211 & $\mathrm{P}$ & 126,10 & $\mathrm{~b}$ & 20,89 & $\mathrm{~b}$ & 16,57 & $\mathrm{a}$ \\
RB946903 & $\mathrm{P}$ & 126,03 & $\mathrm{~b}$ & 20,63 & $\mathrm{~b}$ & 16,38 & $\mathrm{a}$ \\
RB956911 & $\mathrm{P}$ & 115,46 & $\mathrm{c}$ & 18,26 & $\mathrm{c}$ & 15,82 & $\mathrm{a}$ \\
RB966928 & $\mathrm{P}$ & 146,07 & $\mathrm{a}$ & 23,39 & $\mathrm{a}$ & 16,00 & $\mathrm{a}$ \\
RB845210 & $\mathrm{M}$ & 104,39 & $\mathrm{~d}$ & 16,79 & $\mathrm{c}$ & 16,09 & $\mathrm{a}$ \\
RB855113 & $\mathrm{M}$ & 122,69 & $\mathrm{~b}$ & 20,06 & $\mathrm{~b}$ & 16,38 & $\mathrm{a}$ \\
SP81-3250 & $\mathrm{M}$ & 95,98 & $\mathrm{~d}$ & 15,07 & $\mathrm{~d}$ & 15,66 & $\mathrm{a}$ \\
RB935744 & $\mathrm{M}$ & 143,23 & $\mathrm{a}$ & 22,81 & $\mathrm{a}$ & 15,91 & $\mathrm{a}$ \\
RB72454 & $\mathrm{T}$ & 138,59 & $\mathrm{a}$ & 23,02 & $\mathrm{a}$ & 16,62 & $\mathrm{a}$ \\
\hline CV (\%) & & 10,28 & & 10,56 & & 4,03 & \\
\hline
\end{tabular}

Médias seguidas pela mesma letra na vertical não diferem estatisticamente pelo teste de Scott-Knott a 5\% de probabilidade. P: Precoce. M: Médio. T: Tardio

CV: Coeficiente de Variação

Fonte: Elaboração dos autores.

É importante ressaltar que o menor valor de TPH da cana-soca colhida no mês de julho, obtido pelo genótipo de ciclo médio SP81-3250 (15,07 t.ha-1), foi semelhante ao maior valor de TPH obtido na colheita da cana-soca no mês de abril pelo genótipo de ciclo precoce RB966928 (15,49 t.ha- $\left.{ }^{-1}\right)$. Isso ressalta que as condições ambientais não foram favoráveis à colheita da cana-soca no mês de abril. A soqueira do mês de julho encontrou ambiente favorável ao seu rápido crescimento, possibilitando grandes produtividades agrícolas (TCH). Nos meses que antecederam o corte da cana (maio até julho) houve uma significativa queda na temperatura ambiente (Figura 2) e uma seca moderada (Figura 1), o que retardou o crescimento das plantas, induzindo ao acúmulo de sacarose nos colmos, elevando os valores de Pol \% cana e TPH (HUMBRET, 1968; SCARPARI, 2002).
Desempenho de cada genótipo quando colhido em outubro

Os valores de TCH, TPH e Pol \% cana dos dez genótipos, quando colhidos no mês de outubro de 2007, estão apresentados na Tabela 5.

Os genótipos RB72454 (de ciclo tardio) e RB935744 (de ciclo médio) apresentaram médias semelhantes de TCH $(113,50$ e 124,20, respectivamente) e TPH $(18,68$ e 20,14, respectivamente), em cana-soca, as quais não diferiram estatisticamente entre si, e foram superiores às médias dos demais genótipos, quando colhidos em outubro.

Silva, Jerônimo e Lúcio (2008) obtiveram com o genótipo RB72454, em cana-soca, os maiores valores de TCH e TPH, comparando com os valores 
do genótipo IAC86-2480, quando colhidos no mês de setembro.

Vale ressaltar que os genótipos RB835054 e RB925211 (de ciclo precoce) foram os menos produtivos, quanto a TCH e TPH, quando a canasoca foi colhida no mês de outubro. Seus valores, tanto em TCH quanto em TPH foram inferiores à metade dos valores obtidos pelos mesmos genótipos, quando a colheita foi realizada em julho. Isso retrata a inviabilidade de colher esses genótipos após sua época recomendada (até o mês de junho).

Tabela 5. Valores de tonelada de cana por hectare (TCH), tonelada de pol por hectare (TPH) e Pol \% cana (POL) de cana-soca, de dez genótipos colhidos em outubro de 2007 na Unidade Alto Alegre, Colorado, PR.

\begin{tabular}{cccccccc}
\hline Genótipo & Ciclo & TCH & & TPH & POL \\
\hline RB835054 & P & 51,00 & $\mathrm{c}$ & 8,13 & $\mathrm{c}$ & 15,91 & $\mathrm{a}$ \\
RB925211 & $\mathrm{P}$ & 49,97 & $\mathrm{c}$ & 8,02 & $\mathrm{c}$ & 16,00 & $\mathrm{a}$ \\
RB946903 & $\mathrm{P}$ & 78,98 & $\mathrm{~b}$ & 12,89 & $\mathrm{~b}$ & 16,31 & $\mathrm{a}$ \\
RB956911 & $\mathrm{P}$ & 79,21 & $\mathrm{~b}$ & 13,35 & $\mathrm{~b}$ & 16,85 & $\mathrm{a}$ \\
RB966928 & $\mathrm{P}$ & 88,40 & $\mathrm{~b}$ & 14,67 & $\mathrm{~b}$ & 16,59 & $\mathrm{a}$ \\
RB845210 & $\mathrm{M}$ & 81,19 & $\mathrm{~b}$ & 13,23 & $\mathrm{~b}$ & 16,29 & $\mathrm{a}$ \\
RB855113 & $\mathrm{M}$ & 87,61 & $\mathrm{~b}$ & 14,53 & $\mathrm{~b}$ & 16,56 & $\mathrm{a}$ \\
SP81-3250 & $\mathrm{M}$ & 76,31 & $\mathrm{~b}$ & 12,70 & $\mathrm{~b}$ & 16,67 & $\mathrm{a}$ \\
RB935744 & $\mathrm{M}$ & 124,20 & $\mathrm{a}$ & 20,14 & $\mathrm{a}$ & 16,23 & $\mathrm{a}$ \\
RB72454 & $\mathrm{T}$ & 113,50 & $\mathrm{a}$ & 18,68 & $\mathrm{a}$ & 16,45 & $\mathrm{a}$ \\
\hline CV (\%) & & 10,28 & & 10,56 & & 4,03 & \\
\hline
\end{tabular}

Médias seguidas pela mesma letra na vertical não diferem estatisticamente pelo teste de Scott-Knott a 5\% de probabilidade.

P: Precoce. M: Médio. T: Tardio

CV: Coeficiente de Variação

Fonte: Elaboração dos autores.

Todos os genótipos avaliados obtiveram valores altos de Pol \% cana (superiores a 15,9\%), os quais não diferiram estatisticamente entre si.

Os altos valores de Pol \% cana não eram esperados, tendo em vista que as condições ambientais que antecederam a colheita não eram favoráveis ao acúmulo de sacarose, com o aumento das temperaturas e a grande quantidade de chuvas (HUMBRET, 1968; BARBIERI; VILLA NOVA, 1977).

Comportamento dos genótipos em cada época de corte

O desempenho dos dez genótipos de cana-deaçúcar em cana-planta, quanto a TCH, TPH e Pol \% cana, nas três diferentes épocas de colheita, está apresentado na Tabela 6. Para nove dos dez genótipos avaliados, a colheita no mês de julho proporcionou os maiores valores de TCH em cana-soca. Apenas o genótipo de ciclo médio SP81-3250 apresentou médias de TCH semelhantes quando colhido em abril e julho, as quais não diferiram estatisticamente entre si, e foram superiores à média obtida com a colheita em outubro.

Esse resultado de boas produtividades no mês de julho é justificado pelas condições ambientais favoráveis encontradas pelas plantas em todo o seu ciclo de cana-soca. As condições de alta disponibilidade hídrica (Figura 1) e temperaturas médias próximas a $25^{\circ} \mathrm{C}$ (Figura 2) em seu período de grande crescimento (MACHADO, 1981) contribuíram para o rápido crescimento da cultura (DOOREMBOS; KASSAM, 1979; 
PLANALSUCAR, 1986; LIU; KINGSTON; BULL, 1998; ALMEIDA et al., 2008).

Além da produtividade agrícola $(\mathrm{TCH})$, a produção de sacarose (Pol \% cana e TPH) pela cana colhida no mês de julho foi influenciada pelas características ambientais favoráveis. A redução da temperatura e da disponibilidade hídrica nos meses que antecederam a colheita em julho resultou na redução do crescimento das plantas, o que induziu a um maior acúmulo de sacarose nos colmos (HUMBRET, 1968; ALEXANDER, 1973; BARBIERI; VILLA NOVA, 1977; DOOREMBOS; KASSAM, 1979; SCARPARI, 2002).

Tabela 6. Valores de tonelada de cana por hectare (TCH), tonelada de pol por hectare (TPH) e Pol \% cana (POL) na colheita de cana-soca, de dez genótipos colhidos em abril, julho e outubro de 2007 na Unidade Alto Alegre, Colorado, PR.

\begin{tabular}{|c|c|c|c|c|c|c|c|c|}
\hline Genótipo & Ciclo & Época & \multicolumn{2}{|c|}{$\mathrm{TCH}$} & \multicolumn{2}{|c|}{ TPH } & \multicolumn{2}{|c|}{ POL } \\
\hline \multirow{3}{*}{ RB835054 } & \multirow{3}{*}{$\mathrm{P}$} & Abril & 68,28 & B & 9,45 & $\mathrm{~b}$ & 13,87 & $\mathrm{~b}$ \\
\hline & & Julho & 115,84 & A & 18,22 & $\mathrm{a}$ & 15,75 & $\mathrm{a}$ \\
\hline & & Outubro & 51,00 & $\mathrm{C}$ & 8,13 & $\mathrm{~b}$ & 15,91 & $\mathrm{a}$ \\
\hline \multirow{3}{*}{ RB925211 } & \multirow{3}{*}{$\mathrm{P}$} & Abril & 97,75 & B & 14,07 & $\mathrm{~b}$ & 14,39 & $\mathrm{~b}$ \\
\hline & & Julho & 126,10 & A & 20,89 & $\mathrm{a}$ & 16,57 & $\mathrm{a}$ \\
\hline & & Outubro & 49,97 & $\mathrm{C}$ & 8,02 & $\mathrm{c}$ & 16,00 & $\mathrm{a}$ \\
\hline \multirow{3}{*}{ RB946903 } & \multirow{3}{*}{$\mathrm{P}$} & Abril & 78,70 & B & 11,52 & $\mathrm{~b}$ & 14,62 & $\mathrm{~b}$ \\
\hline & & Julho & 126,03 & A & 20,63 & $\mathrm{a}$ & 16,38 & $\mathrm{a}$ \\
\hline & & Outubro & 78,98 & B & 12,89 & $\mathrm{~b}$ & 16,31 & $\mathrm{a}$ \\
\hline \multirow{3}{*}{ RB956911 } & \multirow{3}{*}{$\mathrm{P}$} & Abril & 70,68 & $\mathrm{~B}$ & 10,04 & $\mathrm{c}$ & 14,20 & $\mathrm{~b}$ \\
\hline & & Julho & 115,46 & A & 18,26 & $\mathrm{a}$ & 15,82 & $\mathrm{a}$ \\
\hline & & Outubro & 79,21 & $\mathrm{~B}$ & 13,35 & $\mathrm{~b}$ & 16,85 & $\mathrm{a}$ \\
\hline \multirow{3}{*}{ RB966928 } & \multirow{3}{*}{$\mathrm{P}$} & Abril & 108,97 & B & 15,49 & $\mathrm{~b}$ & 14,16 & $\mathrm{~b}$ \\
\hline & & Julho & 146,07 & A & 23,39 & $\mathrm{a}$ & 16,00 & $\mathrm{a}$ \\
\hline & & Outubro & 88,40 & $\mathrm{C}$ & 14,67 & $\mathrm{~b}$ & 16,59 & $\mathrm{a}$ \\
\hline \multirow{3}{*}{ RB845210 } & \multirow{3}{*}{$\mathrm{M}$} & Abril & 85,91 & B & 11,22 & $\mathrm{~b}$ & 13,09 & $\mathrm{~b}$ \\
\hline & & Julho & 104,39 & A & 16,79 & $\mathrm{a}$ & 16,09 & $\mathrm{a}$ \\
\hline & & Outubro & 81,19 & $\mathrm{~B}$ & 13,23 & $\mathrm{~b}$ & 16,29 & $\mathrm{a}$ \\
\hline \multirow{3}{*}{ RB855113 } & \multirow{3}{*}{$\mathrm{M}$} & Abril & 100,28 & B & 12,28 & $\mathrm{~b}$ & 12,26 & $\mathrm{~b}$ \\
\hline & & Julho & 122,69 & A & 20,06 & $\mathrm{a}$ & 16,38 & $\mathrm{a}$ \\
\hline & & Outubro & 87,61 & $\mathrm{~B}$ & 14,53 & $\mathrm{~b}$ & 16,56 & $\mathrm{a}$ \\
\hline \multirow{3}{*}{ SP81-3250 } & \multirow{3}{*}{ M } & Abril & 95,53 & A & 12,64 & $\mathrm{a}$ & 13,19 & $\mathrm{~b}$ \\
\hline & & Julho & 95,98 & A & 15,07 & $\mathrm{a}$ & 15,66 & $\mathrm{a}$ \\
\hline & & Outubro & 76,31 & $\mathrm{~B}$ & 12,70 & $\mathrm{a}$ & 16,67 & $\mathrm{a}$ \\
\hline \multirow{3}{*}{ RB935744 } & \multirow{3}{*}{$\mathrm{M}$} & Abril & 87,35 & $\mathrm{C}$ & 11,12 & $\mathrm{c}$ & 12,77 & $\mathrm{~b}$ \\
\hline & & Julho & 143,23 & A & 22,81 & $\mathrm{a}$ & 15,91 & $\mathrm{a}$ \\
\hline & & Outubro & 124,20 & B & 20,14 & $\mathrm{~b}$ & 16,23 & $\mathrm{a}$ \\
\hline \multirow{3}{*}{ RB72454 } & \multirow{3}{*}{$\mathrm{T}$} & Abril & 80,63 & $\mathrm{C}$ & 9,97 & $\mathrm{c}$ & 12,36 & $\mathrm{~b}$ \\
\hline & & Julho & 138,59 & A & 23,02 & $\mathrm{a}$ & 16,62 & $\mathrm{a}$ \\
\hline & & Outubro & 113,50 & B & 18,68 & $\mathrm{~b}$ & 16,45 & $\mathrm{a}$ \\
\hline $\mathrm{CV}(\%)$ & & & 10,28 & & 10,56 & & 4,03 & \\
\hline
\end{tabular}

Médias seguidas pela mesma letra na vertical, dentro de cada linha, não diferem estatisticamente pelo teste de Scott-Knott a 5\% de probabilidade.

P: Precoce. M: Médio. T: Tardio

CV: Coeficiente de Variação

Fonte: Elaboração dos autores. 
Os genótipos de ciclo precoce RB835054, RB925211 e RB966928 apresentaram comportamento semelhante quanto à variável $\mathrm{TCH}$, quando colhidos nas diferentes épocas. Esses materiais apresentaram suas maiores médias quando colhidos no mês de julho, seguidas pelo mês de abril, e posteriormente, pelo mês de outubro. Esse comportamento é justificado pelo fato de ambos os genótipos apresentarem ciclo precoce, e também devido às condições ambientais desfavoráveis para a cana-soca colhida no mês de outubro.

A cana-soca colhida no mês de outubro encontrou em seu período de grande crescimento (MACHADO, 1981), condições de deficiência hídrica aliadas a baixas temperaturas, o que pode ter resultado na redução do crescimento(DOOREMBOS; KASSAM, 1979), do perfilhamento (SUGUITANI, 2001; BEZUIDENHOUT, 2003; INMAN-BAMBER, 2004; SMIT; SINGELS, 2006; MACHADO et al., 2009), e também pode ter ocasionado a formação de nós e entrenós mais curtos, prejudicando o acúmulo de sacarose (CÂMARA, 1993).

A cana-soca colhida no mês de outubro ainda encontrou, nos meses que antecederam a colheita, um aumento na disponibilidade hídrica aliada ao aumento da temperatura ambiente, o que induz às plantas a sua retomada do crescimento vegetativo, interrompendo o acúmulo de sacarose (HUMBRET, 1968; BARBIERI; VILLA NOVA, 1977) e resultando em baixas médias de Pol Cana e TPH.

Os genótipos RB946903, RB956911 (de ciclo precoce), RB845210 e RB855113 (de ciclo médio) comportaram-se de forma semelhante quanto à época de corte, apresentando médias semelhantes de TCH quando colhidas em abril e outubro, as quais não diferiram estatisticamente entre si, e foram inferiores às médias obtidas quando colhidos em julho.

Comportamento diferenciado dos demais foi observado nos genótipos RB72454 (de ciclo tardio) e RB935744 (de ciclo médio), os quais apresentaram os maiores valores de TCH e TPH quando colhidos em julho, seguidos de outubro e abril. Comportamento semelhante entre os mesmos também foi observado quanto à variável Pol \% cana, que obteve maiores valores quando a cana foi colhida nos meses de julho e outubro, os quais não diferiram estatisticamente entre si, e foram superiores à média obtida com a colheita no mês de abril. Esse comportamento é justificado pelo fato de ambos os genótipos serem recomendados para colheita a partir de agosto (Tabela 1).

Resultados diferentes foram obtidos por Silva, Jerônimo e Lúcio (2008) em Jaú, no Estado de São Paulo, os quais afirmam que o genótipo RB72454, em cana-soca, apresentou maiores valores de $\mathrm{TCH}$ quando colhido em setembro, em relação às colheitas realizadas em maio e julho. Os mesmos autores obtiveram, com o mesmo genótipo, os menores valores de TPH quando a cana foi colhida em maio, em relação à colheita em julho, sendo que o maior valor foi obtido em setembro.

Quanto à variável TPH, os genótipos RB835054, RB946903, RB966928 (de ciclo precoce), RB845210 e 855113 (de ciclo médio) apresentaram respostas semelhantes às épocas de colheita. Suas médias de TPH, quando colhidos em abril e outubro, não diferiram estatisticamente entre si, e foram inferiores às médias obtidas com a colheita no mês de julho.

Já o genótipo de ciclo precoce RB956911, assim como o de ciclo tardio RB72454 e o de ciclo médio RB935744, apresentou, na colheita em outubro, valores de TPH superiores aos obtidos com a colheita no mês de abril, porém, inferiores aos obtidos com a colheita no mês de julho.

O genótipo de ciclo precoce RB925211 apresentou comportamento diferenciado dos demais, com relação aos valores de TPH. Esse material apresentou, em abril, média superior à obtida no mês de outubro, sendo que ambas foram inferiores à média do mês de julho.

Comportamento único também foi apresentado pelo genótipo de ciclo médio SP81-3250, sendo o único genótipo que não sofreu influência das épocas de corte em seus valores de TPH, em cana-soca. 
Os dez genótipos avaliados apresentaram comportamentos semelhantes quanto à variável Pol $\%$ cana. Todos apresentaram valores semelhantes quando colhidos nos meses de julho e outubro, os quais não diferiram estatisticamente entre si, e foram superiores às médias obtidas com a colheita no mês de abril.

Os valores de Pol \% cana foram inferiores no mês de abril devido às condições ambientais ocorridas nesse período, que podem ser observadas na Figura 01, a qual apresenta as condições de deficiência hídrica que o solo apresentou nos cinco primeiros meses após o corte da cana-planta, que podem ter sido responsáveis pela formação de entrenós mais curtos e próximos entre si, o que reduzirá muito o volume do parênquima para armazenamento de sacarose (CÂMARA, 1993). A grande reposição e o excedente de água existente no solo aliados ao aumento na temperatura ambiente (Figura 2), nos meses que antecederam o corte da cana, podem ter ocasionado o aparecimento dos brotões, os quais apresentam comportamento similar ao de uma cana jovem (BONNETT et al., 2005; CARLIN; SILVA; ROSSETTO, 2008). Esses brotões atuam como um dreno, utilizando os fotoassimilados que seriam translocados para o acúmulo de sacarose, resultando em baixos valores de Pol \% cana e TPH obtidos na colheita no mês de abril (HUMBRET, 1968; ALEXANDER, 1973; BARBIERI; VILLA NOVA, 1977; DOOREMBOS; KASSAM, 1979; OMETTO, 1980; YAMORI; NOGUCHI; TERASHIA, 2005).

\section{Conclusões}

Com a realização do presente trabalho, pode-se concluir que as épocas de corte exerceram influência sobre a produtividade agroindustrial dos genótipos de cana-de-açúcar.

A tomada de decisões para colher os genótipos de cana-de-açúcar não deve ser baseada apenas nos padrões tecnológicos, com valor superior a $13 \%$ de Pol \% cana. Um alto valor de Pol \% cana pode não significar alta produtividade agroindustrial, tendo em vista que essa característica depende também da produtividade agrícola.

É necessária a continuação desses estudos, englobando diferentes ambientes de produção, além de considerar também as socas subseqüentes.

\section{Referências}

ALENCAR, C. E. R.; CORRÊA, R. F.; LIMA NETO, R. B. de. Ferramenta para suporte à decisão de frentes de corte de cana-de-açúcar usando algoritmos genéticos. 2006. Monografia (Conclusão de Curso) - Escola Politécnica. Universidade de Pernambuco, Recife.

ALEXANDER, A. G. Sugarcane physiology. A comprehensive study of the Saccharum source-to-sink system. Amsterdam: Elsevier, 1973. 725 p.

ALMEIDA, A. C. S.; SOUZA, J. L.; TEODORO, I.; BARBOSA, G. V. S. B.; MOURA FILHO, G.; FERREIRA JÚNIOR, R. A. F. Desenvolvimento vegetativo e produção de variedades de cana-de-açúcar em relação a disponibilidade hídrica e unidades térmicas. Ciência e Agrotecnologia, Lavras, v. 32, n. 5, p. 14411448, 2008.

BARBIERI, V.; VILLA NOVA, N. A. Climatologia $e$ a cana-de-açúcar. Araras: PLANALSUCAR Coordenadoria Regional Sul - COSUL, 1977. 22 p.

BEZUIDENHOUT, C. N.; O’LEARY, G. J.; SINGELS, A.; BAJIC, V. B. A process-based model to simulate changes in tiller density and light interception of sugarcane crops. Agricultural Systems, Amsterdam, v. 76, n. 2, p. 589-599, 2003.

BONNETT, G. D.; SALTER, B.; BERDING, N.; HURNEY, A. P. Environmental stimuli promoting sucker initiation in sugarcane. Field Crops Research, Amsterdam, v. 92, n. 1, p. 219-230, 2005.

BORGES, L. C.; FERREIRA, D. F. Poder e taxas de erro tipo I dos testes Scott-Knott, Tukey e StudentNewman-Keuls sob distribuições normal e não normais dos resíduos. Rev. Mat. Estat., São Paulo, v. 21, n. 1, p. 67-83, 2003.

CÂMARA, G. M. S. Ecofisiologia da cultura da canade-açúcar. In: CÂMARA, G. M. S.; OLIVEIRA, E. A. M. (Ed.). Produção da cana-de-açúcar. Piracicaba: FEALQ, 1993, p. 31-64.

CARLIN, S. D.; SILVA, M. A.; ROSSETTO, R. Parâmetros biométricos e produtividade da canade-açúcar após tombamento de colmos. Bragantia, Campinas, v. 67, n. 4, p. 845-853, 2008. 
CONSECANA - CONSELHO DOS PRODUTORES DE CANA-DE-AÇÚCAR, AÇÚCAR E ÁLCOOL DO ESTADO DE SÃO PAULO. Manual de instruções. Piracicaba: CONSECANA, 1999. 92 p.

COPERSUCAR - COOPERATIVA CENTRAL DOS PRODUTORES DEAÇÚCARE ÁLCOOLDOESTADO DE SÃO PAULO. Variedades SP: recomendações e manejo. In: REUNIÃO TÉCNICA COPERSUCAR, 1983. São Paulo. Anais... São Paulo: Copersucar, 1983. p. $44-56$.

DIAS, J. A. Cana-de-açúcar. Curitiba: Companhia Nacional de Abastecimento, Superintendência Regional do Paraná/CONAB, 2008.

DOOREMBOS, J.; KASSAM, A. H. Efectos del água sobre el rendimiento de los cultivos. Roma: FAO, 1979. 212 p. (FAO. Riego y Drenaje, 33).

EMPRESA BRASILEIRA DE PESQUISA AGROPECUÁRIA - EMBRAPA. Centro Nacional de Pesquisa de Solos (Rio de Janeiro, RJ.). Sistema brasileiro de classificação de solos. Brasília: Embrapa Produções de informações; Rio de Janeiro: Embrapa Solos, 1999, 412 p.

HUMBRET, H. P. The growing of sugarcane. Amsterdam: Elsevier, 1968. 779 p.

INSTITUTO AGRONÔMICO DO PARANÁ - IAPAR. Cartas climáticas do Estado do Paraná. Londrina: IAPAR, 1994, 49 p. (IAPAR. Documento, 18).

INMAN-BAMBER, N. G. Sugarcane water stress criteria for irrigation and drying off. Field Crops Research, Amsterdam, v. 89, n. 1, p. 107-122, 2004.

LIU, D. L.; KINGSTON, G.; BULL, T. A. A new technique for determining the thermal parameters of phonological development in sugarcane, including sub optimum and supre-optimum temperature regiments. Agricultural and Forest Meteorology, Amsterdam, v. 90, n. 1, p. 119-139, 1998.

MACHADO, E. C. Um modelo matemático-fisiológico para simular o acúmulo de matéria seca na cultura da cana-de-açúcar (Saccharum spp.). 1981. Dissertação (Mestrado em Biologia Vegetal) - Instituto de Biologia. Universidade Estadual de Campinas, Campinas.

MACHADO, R. S.; RIBEIRO, V.; MARCHIORI, P. E. R.; MACHADO, D. F. S. P.; MACHADO, E. C.; LANDELL, M. G. A. Respostas biométricas e fisiológicas ao déficit hídrico em cana-de-açúcar em diferentes fases fenológicas. Pesquisa Agropecuária Brasileira, Brasília, v. 44, n. 12, p. 1575-1582, 2009.

MINISTÉRIO DA AGRICULTURA, PECUÁRIA E ABASTECIMENTO - MAPA. Balanço Nacional da cana-de-açúcar e agroenergia. Secretaria de Produção e Agroenergia. Brasília, MAPA/SPAE, 2007.

Produção Brasileira de cana-de-açúcar. 2009.

Disponível em: $<$ http://www.agricultura.gov.br $>$. Acesso em: 01 abr. 2009.

MENDONÇA, J. R. de; NOCITI, P. R. H.; DEOTTI, R. C. Estudo de diferentes épocas de corte em cana-de-açúcar. In: SEMINÁRIO DE TECNOLOGIA AGRONÔMICA, 2., 1984, Piracicaba. Anais... Piracicaba: Centro de Tecnologia Copersucar, 1984. p. 140-149.

OMETTO, J. C. Parâmetros meteorológicos e a cultura da cana-de-açúcar. Piracicaba: ESALQ. 1980. 17 p.

PLANALSUCAR. Cultura da cana-de-açúcar: manual de orientação. Piracicaba: IAA, Coordenadoria Regional Sul, 1986. $56 \mathrm{p}$.

PRADO, H. Solos do Brasil: gênese, morfologia, classificação, levantamento, manejo agrícola e geotécnico. 3 ed. rev. e ampl. Piracicaba: ESALQ/USP, 2003. 275 p.

SCARPARI, M. S. Modelos para a previsão da produtividade da cana-de-açúcar (Saccharum spp.) através de parâmetros climáticos. 2002. Dissertação (Mestrado em Agronomia - Fitotecnia) - Escola Superior de Agricultura Luiz de Queiroz. Universidade de São Paulo, Piracicaba.

SILVA, M. A.; JERONIMO, E. M.; LÚCIO, A. D. C. Perfilhamento e produtividade de cana-de-açúcar com diferentes alturas de corte e épocas de colheita. Pesquisa Agropecuária Brasileira, Brasília, v. 43, n. 8, p. 979-986, ago. 2008.

SMIT, M. A.; SINGELS, A. The response of sugarcane canopy development to water stress. Field Crops Research, Amsterdam, v. 98, n. 2-3, p. 91-97, 2006.

SUGUITANI, C. Fenologia da cana-de-açúcar (Saccharum spp.) sob efeito do fósforo. 2001. Dissertação (Mestrado em Agronomia, Fitotecnia) - Escola Superior de Agricultura Luiz de Queiroz. Universidade de São Paulo, Piracicaba.

TAVARES, A. C. S. Sensibilidade da cana-de-açúcar (Saccharum spp.) ao excesso de água no solo. Tese (Doutorado em Agronomia) - Escola Superior de Agricultura Luiz de Queiroz. Universidade de São Paulo, Piracicaba.

YAMORI, W.; NOGUCHI, K.; TERASHIMA, I. Temperature acclimation of photosynthesis in spinach leaves: analysis of photosynthetic components and temperature dependencies of photosynthetic partial reactions. Plant Cell Environmental, Logan, USA, v. 28, n. 4, p. 536-547, 2005. 